\title{
CHROMATOGRAPHIC SEPARATION OF THE SODIUM-RETAINING CORTICOID FROM THE URINE OF CHILDREN WITH NEPHROSIS, COMPARED WITH OBSERV.A- TIONS ON NORMAL CHILDREN ${ }^{1,2}$
}

\author{
By JOHN A. LUETSCHER, JR., AND BEN B. JOHNSON
}

WITH THE ASSISTANCE OF

ANNE DOWDY, JULIA HARVEY, W. LEW, and L. J. POO

(From the Department of Medicine, Stanford University School of Medicine, San Francisco, Calif.)

(Submitted for publication August 7, 1953; accepted October 2, 1953)

Previous studies in this laboratory have indicated that a high degree of sodium-retaining activity may be present in chloroform extracts of urine of certain patients with edema (2-6). When patients with the nephrotic syndrome are treated with ACTH or cortisone, the increased excretion of sodium in the urine is associated with a reduction in the sodium-retaining activity of the lipid extract $(4,5)$. Comparable extracts of urine of normal children or adults show slight activity and may even promote the excretion of sodium in the bioassay used. When the dietary intake of sodium is decreased, a moderate increase in sodium-retaining activity of the urine extract may be observed.

These findings suggest that the sodium-retaining activity of the lipid extract may reflect a stimulus to conserve sodium. Further studies of the origin, regulation, and function of the observed sodium-retaining activity require more definitive study of the material responsible for this biological activity. Some observations on fractionation of active extracts by displacement chromatography (7) and by paper partition chromatography have indicated that the sodium-retaining activity is due to an unidentified corticoid which contains more oxygen than desoxycorticosterone (6). Systematic analysis of highly active extracts by chromatography was therefore undertaken to ob-

1 This project was supported by research grants (HG163 and A-119) from the National Heart Institute and the National Institute of Arthritis and Metabolic Diseases, Public Health Service.

2 A brief report of these studies was read before the 45 th Annual Meeting of the American Society for Clinical Investigation, Atlantic City, May 4, 1953 (1). tain further information on the nature of the sodium-retaining component $(1,8)$.

\section{PATIENTS}

The five children with the nephrotic syndrome showed generalized edema, proteinuria, hypoalbuminemia, and hyperlipemia at the time of urine collection. These patients excreted less than $1 \mathrm{mEq}$. of sodium in the urine. Dietary intake ranged between 5 and $17 \mathrm{mEq}$. of sodium per day. All patients responded to subsequent treatment with ACTH, cortisone, or hydrocortisone with a diuresis and reduced proteinuria. Two patients have subsequently recovered, two still show evidences of active renal disease, and one died of pulmonary embolism.

Four normal male children served as controls. All received an unrestricted intake of sodium and water during the period of urine collection. Table I presents some pertinent data.

\section{METHODS}

Urine was collected as 24 hour specimens without preservative and held at $4^{\circ} \mathrm{C}$. At the end of a collection period of one to five days, it was pooled and either extracted or frozen. Several observations showed a loss of sodium-retaining activity in specimens which had been allowed to stand over chloroform at $4^{\circ} \mathrm{C}$. for more than a few days.

Urine was acidified to $\mathrm{pH} 1.0$ with concentrated hydrochloric acid and was extracted with four aliquots of 0.2 volume of chloroform. The chloroform extracts were combined and washed twice with 0.1 volume of $\mathrm{N} / 10$ solution of sodium hydroxide and once with 0.1 volume of water. The chloroform was dried over anhydrous sodium sulfate and evaporated to dryness in vacuo at $40^{\circ} \mathrm{C}$., and the residue was taken up in 95 per cent ethanol. This "washed extract" has been kept for more than a year at $4^{\circ} \mathrm{C}$. with little loss of sodium-retaining activity.

The alkali and water "washings" were acidified and reextracted with chloroform, which was then dried and evaporated. The residue was stored in ethanol.

Extracts and appropriate standards were analyzed by chromatography, following the techniques of Burton, Zaf- 
TABLE I

Clinical data and urine findings

\begin{tabular}{|c|c|c|c|c|c|c|}
\hline Patient & $\begin{array}{c}\text { Age } \\
\text { years }\end{array}$ & Sex & $\begin{array}{l}\text { Urine } \\
\text { volume } \\
c c . / 24 \mathrm{hr} \text {. }\end{array}$ & $\begin{array}{l}\text { Protein } \\
\mathrm{Gm} . / 24 \mathrm{hr}\end{array}$ & $\underset{m E q . / 24 h r .}{\text { Sodium }}$ & $\begin{array}{l}\text { Bioassay } \\
\text { Mg. DOCA equiv. } \\
\text { per } 20 \text { mins. }\end{array}$ \\
\hline \multicolumn{7}{|c|}{ Group I : Nephrosis with edema } \\
\hline $\begin{array}{l}\text { GJ } \\
\text { CK } \\
\text { MR } \\
\text { LM } \\
\text { DM }\end{array}$ & $\begin{array}{l}2 \\
4 \\
5 \\
7 \\
7\end{array}$ & $\begin{array}{l}\mathrm{M} \\
\mathrm{F} \\
\mathrm{M} \\
\mathrm{M} \\
\mathrm{M}\end{array}$ & $\begin{array}{l}196 \\
765 \\
593 \\
365 \\
220\end{array}$ & $\begin{array}{l}1.7 \\
7.3 \\
4.8 \\
4.8 \\
3.1\end{array}$ & $\begin{array}{l}0.9 \\
0.4 \\
0.5 \\
0.8 \\
0.3\end{array}$ & $\begin{array}{l}8.4 \\
8.1 \\
8.2 \\
7.8 \\
8.4\end{array}$ \\
\hline \multicolumn{7}{|c|}{ Group II : Normal } \\
\hline $\begin{array}{l}\text { GG } \\
\text { RG } \\
\text { RA } \\
\text { BL }\end{array}$ & $\begin{array}{r}3 \\
3 \\
5 \\
11\end{array}$ & $\begin{array}{l}\mathbf{M} \\
\mathbf{M} \\
\mathbf{M} \\
\mathbf{M}\end{array}$ & $\begin{array}{l}500 \\
255 \\
605 \\
980\end{array}$ & $\frac{-}{E}$ & $\begin{array}{c}71.0 \\
\overline{91.2} \\
84.3\end{array}$ & $\begin{array}{r}0.5 \\
0.5 \\
-0.5 \\
-0.3\end{array}$ \\
\hline
\end{tabular}

faroni, and Keutmann (9) and of Bush (10). Filter paper sheets (Whatman No. 1) $12.5 \mathrm{~cm}$. by 35 to $45 \mathrm{~cm}$. were washed with 95 per cent ethanol. A cut was made from the bottom of the sheet to a point just above the starting line to form two limbs. The urine extract (in amount equivalent to 400 to 1,000 minutes of urine collection) was placed on one limb. Known crystalline steroids were placed on the other limb to serve as standards. When the chromatogram had been developed by flow of the moving solvent the paper was dried in a stream of warm air. A contact print was made on photographic paper following the method described by Haines (11), using a source emitting light at $254 \mathrm{~m} \mu$. This photograph served as a permanent record and as an indicator of the positions of standard steroids and unknown components absorbing ultraviolet light. The paper was cut to separate the bands demonstrated in the photograph. These sections of paper were eluted with 95 per cent ethanol.

Ultraviolet absorption curves were determined in a Beckman DU spectrophotometer. The optical density contributed by the paper appeared as a steeply falling curve with absorption maximum less than $212 \mathrm{~m} \mu$ (Figure 10). This paper blank did not interfere seriously with the measurements if appreciable quantities of steroid were present and if the paper had been thoroughly pre-washed.

TABLE II

Standard corticosteroids and symbols used

Sodium-retaining in bioassay

11-desoxycorticosterone

17-hydroxy-11-desoxycorticosterone

Sodium-diuretic in bioassay

11-dehydrocorticosterone

Corticosterone

17-hydroxy-11-dehydrocorticosterone

17-hydroxy-corticosterone

"Tetrahydro" compounds

Allopregnane-3,11,21-triol-20-one

Allopregnane-3,17,21-triol-20-one

Allopregnane-3,17,21-triol-11,20-dione

Allopregnane-3,11,17,21-tetrol-20-one
DOC

S (Reichstein)

A (Kendall)

B (Kendall)

E (Kendall)

F (Kendall)

$\mathrm{R}$ (Reichstein)

$P$ (Reichstein)

D (Reichstein)

V (Reichstein)
Since the absorption maxima of $\alpha, \beta$-unsaturated ketones (about $240 \mathrm{~m} \mu$ ) and of paper blank (less than $212 \mathrm{~m} \mu$ ) are different, and when the ratio of absorption at 240 and at a shorter wave length (e.g., $220 \mathrm{~m} \mu$ ) is known, a correction for paper blank can be applied to the density at $240 \mathrm{~m} \mu$, yielding the density due to steroid. The corrected density $\left(D^{\prime}{ }_{240}\right)$ has been translated to concentration, using $E_{\max }=15,800(12,13)$. When eluates contained material which gave absorption curves or maxima other than those expected from paper or from an $\alpha, \beta$-unsaturated ketone, no estimate of concentration has been made, as indicated in the charts by a question mark.

Reduction of neotetrazolium by the various eluates was measured by a micro-modification of the technique of Mader and Buck (14).

Bioassay of sodium-retaining activity was carried out by a modification by Johnson (15) of methods previously described (3). This assay is based on the excretion of sodium and potassium by nine adrenalectomized rats, the effect of the "unknown" being compared with the effect of the control solvent and of $5 \mu \mathrm{g}$. of desoxycorticosterone acetate. Confidence intervals (95 per cent) have been calculated by statistical analysis of assays using known doses of DOCA between 0 and $10 \mu \mathrm{g}$. as the "unknown." The bioassay data presented are calculated from changes in the potassium to sodium ratio, which gives a more precise estimate than that calculated from sodium output (15). In the range of dosage used, the main effect of DOCA and of active extracts and fractions from urine is a reduction of sodium excretion, while increases in potassium excretion are less striking.

In this assay, the 11-oxysteroids (Kendall's A, B, E, and $F$ ) produce an increased output of sodium, which is reflected in the assay calculation by an estimate significantly less than zero dose. Of the adrenocortical steroids tested, only 11-desoxycorticosterone and several derivatives lacking oxygen on C-11 (e.g., Reichstein's S) cause retention of sodium. Table II indicates symbols used in text and figures. 


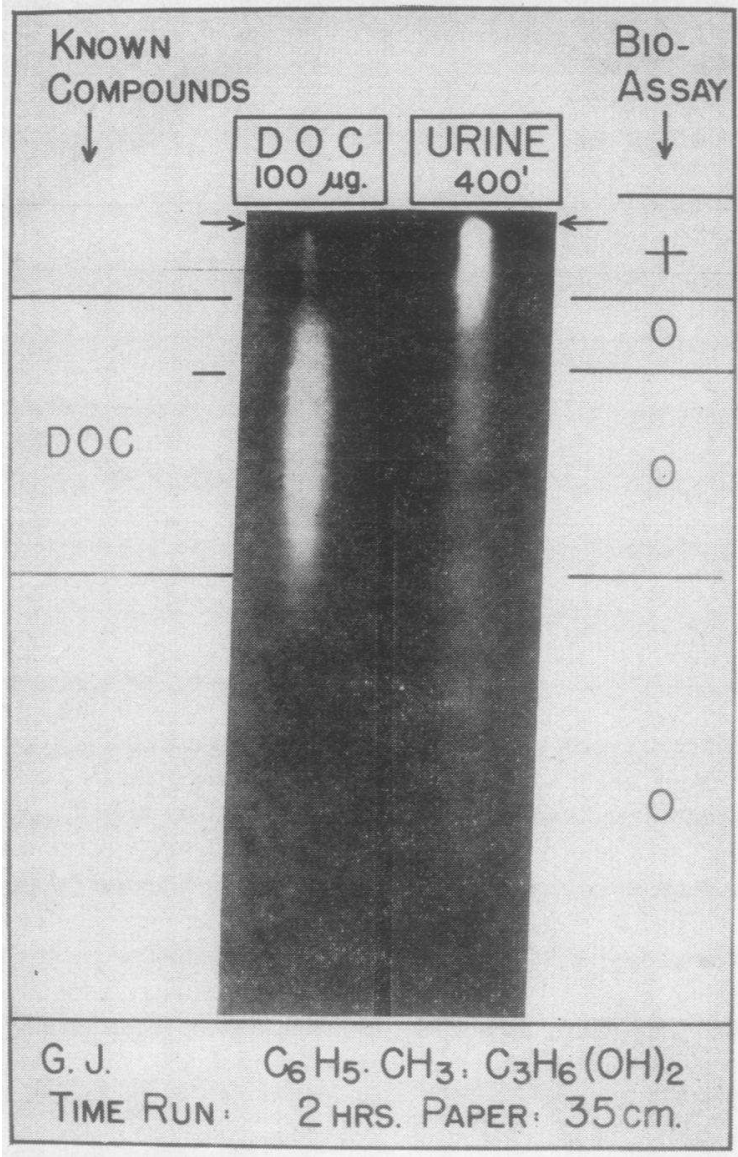

Fig. 1. Descending Chromatogram of Urine Extract (Limb on Right) and Desoxycorticosterone (Standard Limb on Left) in Tollene: Propylene Glycol for Two Hours

Compounds absorbing ultraviolet light are shown as light areas on the negative photographic print. The chromatogram was subsequently cut along the lines extending from each side. The results of bioassays of the eluates from each section of the urine chromatogram are indicated on the right. Significant sodium-retaining activity is shown by a + mark in the fraction moving more slowly than DOC. No significar.t sodium-retaining effect (O) was observed in the eluates in which free DOC present in the urine extract would be found.

\section{RESULTS}

\section{Patients with the Ncphrotic Syndrome}

The urine of these five patients yielded extracts of high sodium-retaining activity equivalent to between 7.8 and $8.4 \mu \mathrm{g}$. of DOCA per 20 minutes of urine (Table I). Urine volume does not appear to have any clear effect on the activity of the extract (Table I). Some data presented else- where (3) indicate that proteinuria is not an important factor in the sodium-retaining activity of the extract.

"Washing" of the chloroform extract with sodium hydroxide solution removed most of the pigments and much of the bulk of the urine extract without loss of sodium-retaining activity. No activity was recovered from the alkali-soluble material on re-extraction and bioassay.

Chromatography in toluene and propylene glycol was used to fractionate the "washed extract." Representative chromatograms on patient G. J. are presented in Figures 1 to 3 and summarized in

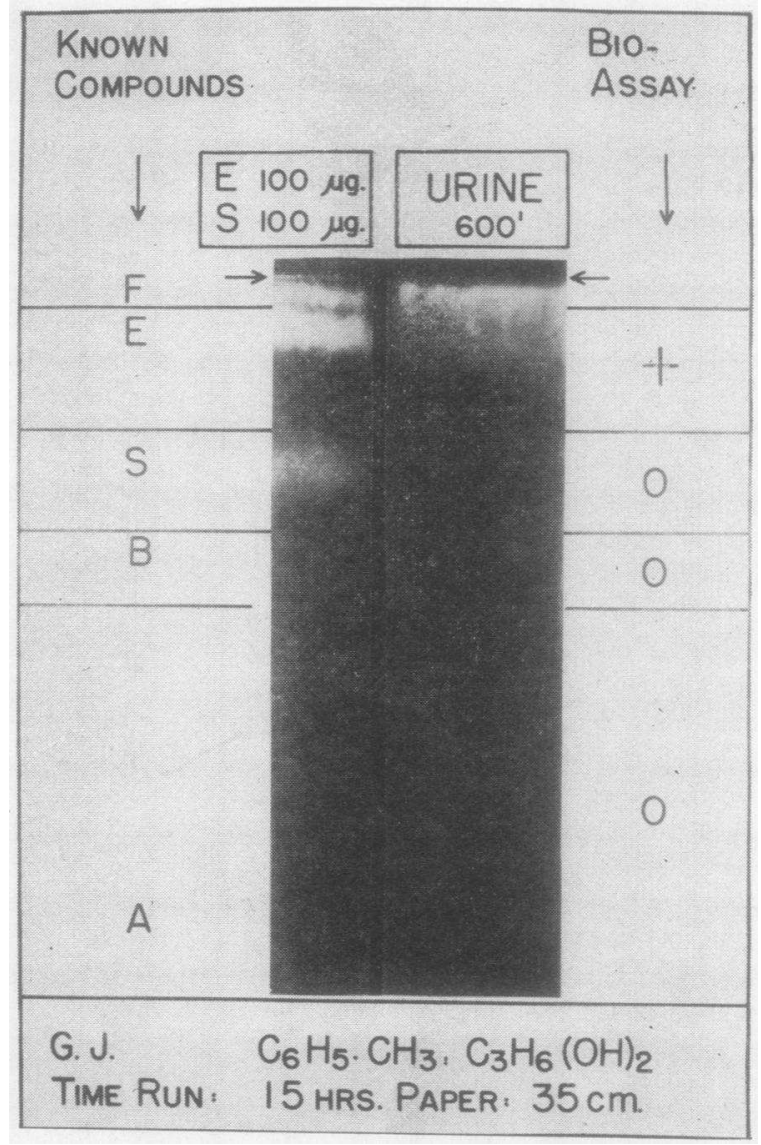

Fig. 2. Descending Chromatogram of Urine Extract (Limb on Right) and Standards (Limb on Left) in Tollene: Propylene Glycol for Fifteen Hours

The sodium-retaining activity (Bioassay + ) appeared in the eluate of a fraction running at a rate equal to or slightly greater than cortisone (E). No significant sodium-retaining effect was found in the fraction corresponding to $\mathrm{S}$. The expected positions of $\mathrm{B}$ and $\mathrm{A}$ were calculated from the position of $S$ by the known ratio of mobilities. 
Figure 4. In Figure 1, the solvent front is at the bottom of the paper strip, which thus contains all of the original extract. The least polar fraction at the bottom of the paper did not contain appreciable quantities of material which absorbed ultraviolet light at $240 \mathrm{~m} \mu$ or which reduced tetrazolium reagent. The middle two fractions, which would include any free DOC present in the extract, contained less than $0.3 \mu \mathrm{g}$. of corticosteroid per 20 minutes of urine, as measured either by absorption of ultraviolet light or by reduction of tetrazolium. These fractions were inert on bioassay. All of the sodium-retaining activity of the extract was found in the most polar fraction. This fraction was subjected to more prolonged chromatography, as shown in Figures 2 and 3.

Figure 2 shows a 15 hour chromatogram, which would include compounds $\mathrm{F}, \mathrm{E}, \mathrm{S}, \mathrm{B}$, and $\mathrm{A}$ in descending order. The sodium-retaining activity was found in the region opposite the compound $\mathrm{E}$ standard. Small quantities of corticosteroids were present in fractions corresponding with $\mathrm{B}, \mathrm{E}$, and F. All fractions except the one moving with $\mathrm{E}$ failed to show significant sodium-retaining activity.

Figure 3 represents a chromatogram of 144 hours duration. The components of the extract moving at about the same rate as $E$ yielded two incompletely separated ultraviolet absorption bands. The slower moving of these two fractions contained the sodium-retaining activity of the extract. This fraction absorbed ultraviolet light $\left(\lambda{ }_{\max }^{\mathrm{EtOH}}\right.$ 236 to $238 \mathrm{~m} \mu$.) and reduced tetrazolium in the corresponding amounts which would be expected from a typical adrenal cortical steroid (Figure 4). This fraction might contain cortisone, but since cortisone is not sodium-retaining under the condition of the assay used, there must also be at least one other compound present in order to account for the activity. The separation of these two substances does not appear to be feasible in the toluene-propylene glycol system.

The $\mathrm{E}$ fraction may contain a third substance, which is partly resolved from cortisone and the sodium-retaining material in the toluene-propylene glycol system. This is indicated by the higher ultraviolet absorption of the faster-moving material, whereas the tetrazolium reducing power and the sodium-retaining activity are lower than in the slower-moving fraction. The data suggest

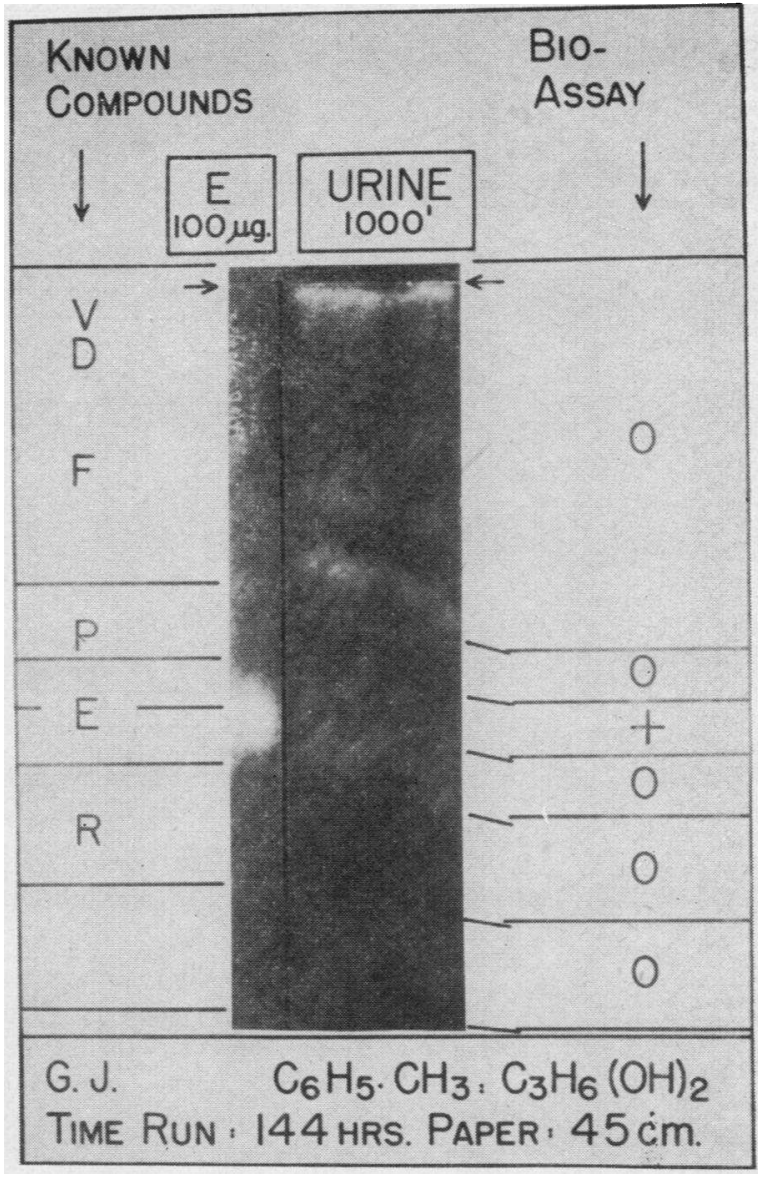

Fig. 3. Descending Chromatogram of Urine Extract (Limb on Right) and Standards (Limb on Left) in Toluene: Propylene Glycol for 144 Hours

that this separation occurred in two cases (Figures 4 and 5), but not in the other two cases (Figures 6 and 7 ).

Figures 4 to 7 summarize the similar analyses of the chromatograms of four patients. In each case, the sodium-retaining activity of the extract was recovered in the " $E$ " fraction, within the limits of the methods used. No significant sodiumretaining activity was found in any other fraction.

The quantitative data show a high degree of biological activity when compared with the absorption of ultraviolet light and with the reduction of tetrazolium. The sodium-retaining activity of the $\mathrm{E}$ fraction is at least ten times as great as desoxycorticosterone, if the active material is a steroid which reduces tetrazolium.

Chromatography in benzene and aqueous methanol: It was evident at this stage that the resolu- 


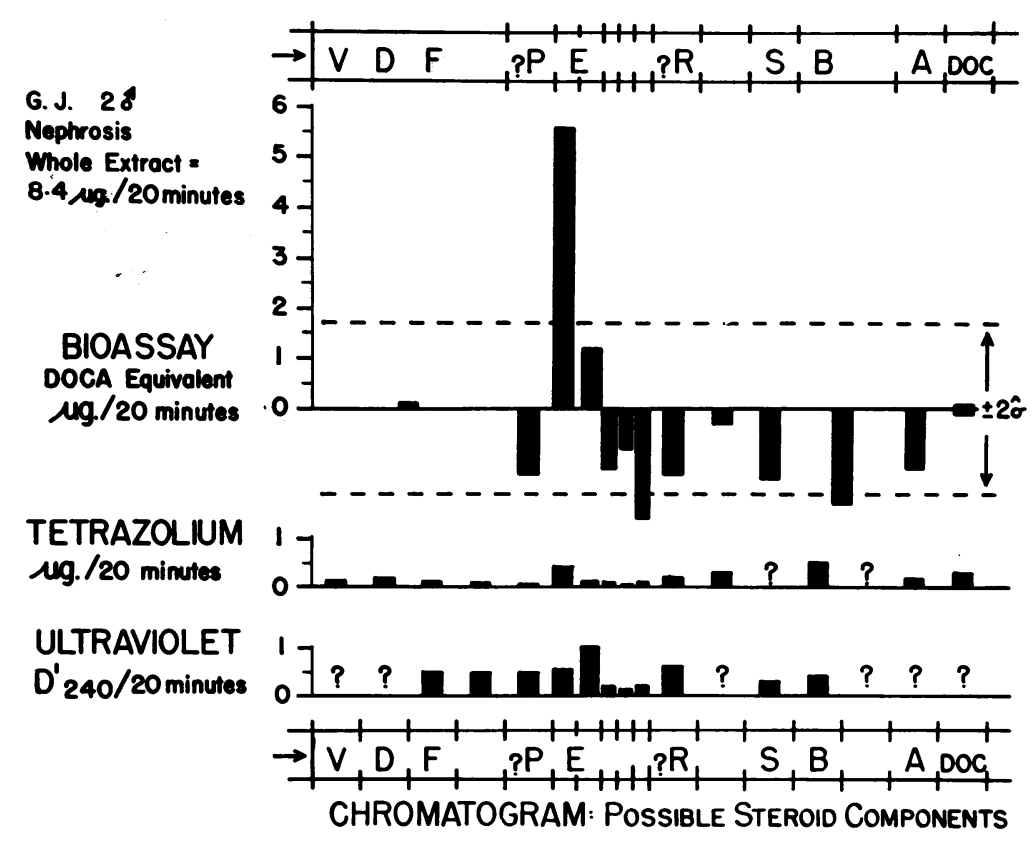

Fig. 4. Sodium-Retaining Activity, Tetrazolium Reduction, and Ultraviolet light Absorption Determined in Eluates from ChromaTOGRAMS (CASE G. J.)

A continuous chromatogram is represented at top and bottom, with symbols representing standard steroids (Table II). Vertical lines on the upper chromatogram demarcate the sections eluted for bioassay; on the lower chromatogram for tetrazolium reduction and ultraviolet light absorption. Bars indicate determinations using desoxycorticosterone as a standard. Bioassay results may be compared with the broken lines showing calculated 95 per cent confidence limits of response to zero dosage. The only eluate showing sodium-retaining activity was the slower portion of the " $E$ " fraction. The sodium-retaining activity of this fraction is very high in comparison with the small amount of corticosteroid indicated by absorption of ultraviolet light and by reduction of tetrazolium.

tion of the $\mathrm{E}$ fraction in toluene: propylene glycol was not adequate for the purification of the active material. While we were casting about for a different pair of solvents of greater resolving power, we received a generous communication of unpublished information from Dr. J. F. Tait and Mr. S. A. Simpson concerning their experience with the benzene:aqueous methanol system developed by Dr. Ian Bush (10). Simpson and Tait (16) have found that the highly active mineralo-corticoid of adrenal cortical extract can be separated from cortisone in Bush's system. The following data indicate that separation of the urinary corticoids of the $\mathrm{E}$ fraction can be accomplished in a similar manner.

Figure 8 shows an $\mathrm{E}$ fraction from toluene: propylene glycol, rechromatographed in the Bush system. The active material runs less rapidly than cortisone, but more rapidly than $\mathrm{F}$.

Figure 9 summarizes the data from two such chromatograms. The fraction associated with the sodium-retaining activity is separated from the faster-moving cortisone, and from more slowly moving fractions. Within the limits of the methods used, the activity of the whole extract appears in this fraction.

The sodium-retaining material obtained from these chromatograms gives the typical reactions of an adrenal cortical steroid. Solutions in ethanol show a peak of ultraviolet light absorption at 238 to $240 \mathrm{~m} \mu$ (Figure 10). If the molar extinction coefficient is assumed to be 15,800 , from which value the known corticosteroids vary only slightly $(12,13)$, the quantity calculated to be present is 
M.R. 5 \&

Nephrosis

Woshed Extrect =

8.2 $\mu \mathrm{g}$. $/ 20$ minutes

BIOASSAY

DOCA Equivalent

Ng./20 minutes
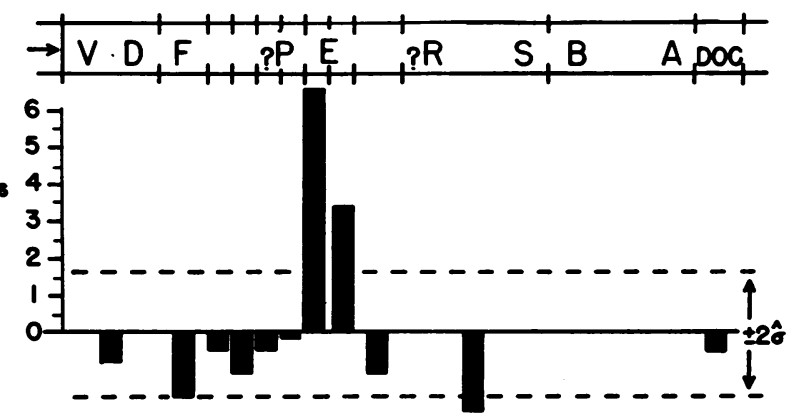

TETRAZOLIUM ug. /20 minutes

ULTRAVIOLET

$D_{240 / 20 \text { minutes }}^{\prime}$

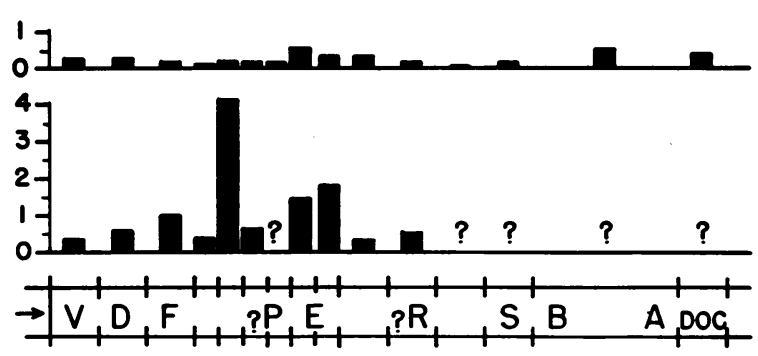

CHROMATOGRAM: POSSible STEROId COMPONENTS

Fig. 5. Sodium-Retaining Activity, Tetrazolium Reduction, and Ultraviolet Light Absorption Determined in Eluates from ChromaTOGRAMS (CASE M. R.)

See explanatory note under Figure 4.

\section{M. 78}

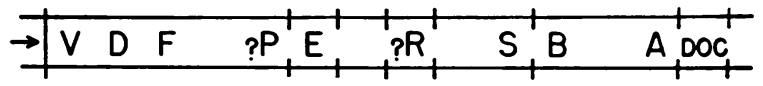

Nephrosis

Whole Extroct =

$7.8 \mathrm{Ng} / 20$ minutes

BIOASSAY

DOCA Equivalent

ug./20 minutes

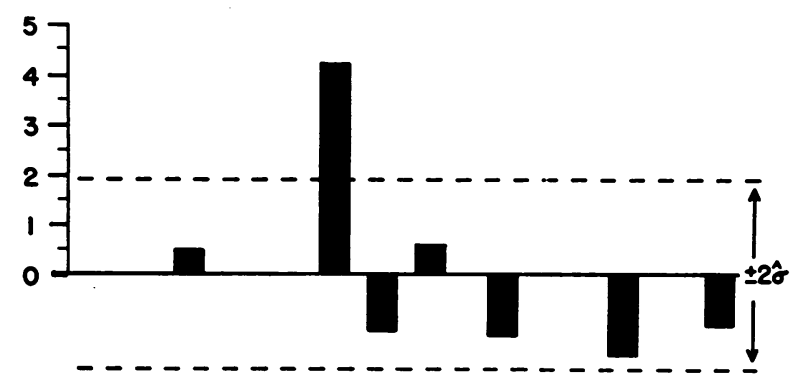

TETRAZOLIUM ug/20 minutes

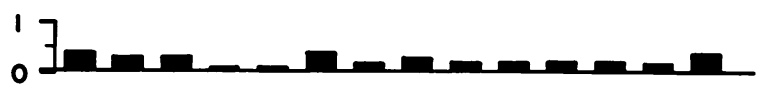

ULTRAMOLET

$D_{240 / 20 \text { minutes }}^{\prime}$

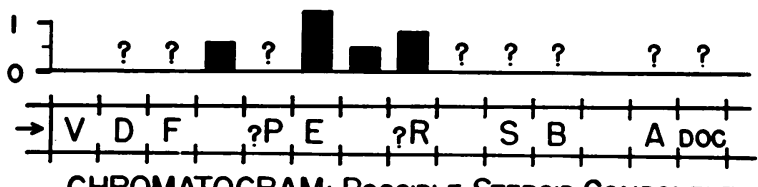

CHROMATOGRAM: POSSIBLE STEROID COMPONENTS

Fig. 6. Sodium-Retaining Activity, Tetrazolium Reduction, and Ultraviolet Light Absorption Determined in Eluates from ChromaTOGRAMS (CASE L. M.)

High sodium-retaining activity was again found in the $\mathrm{E}$ fraction. Since the active material was not separated from the component of slightly greater mobility as in Figures 3 to 5, the absorption of ultraviolet light was increased by the presence of this component. 


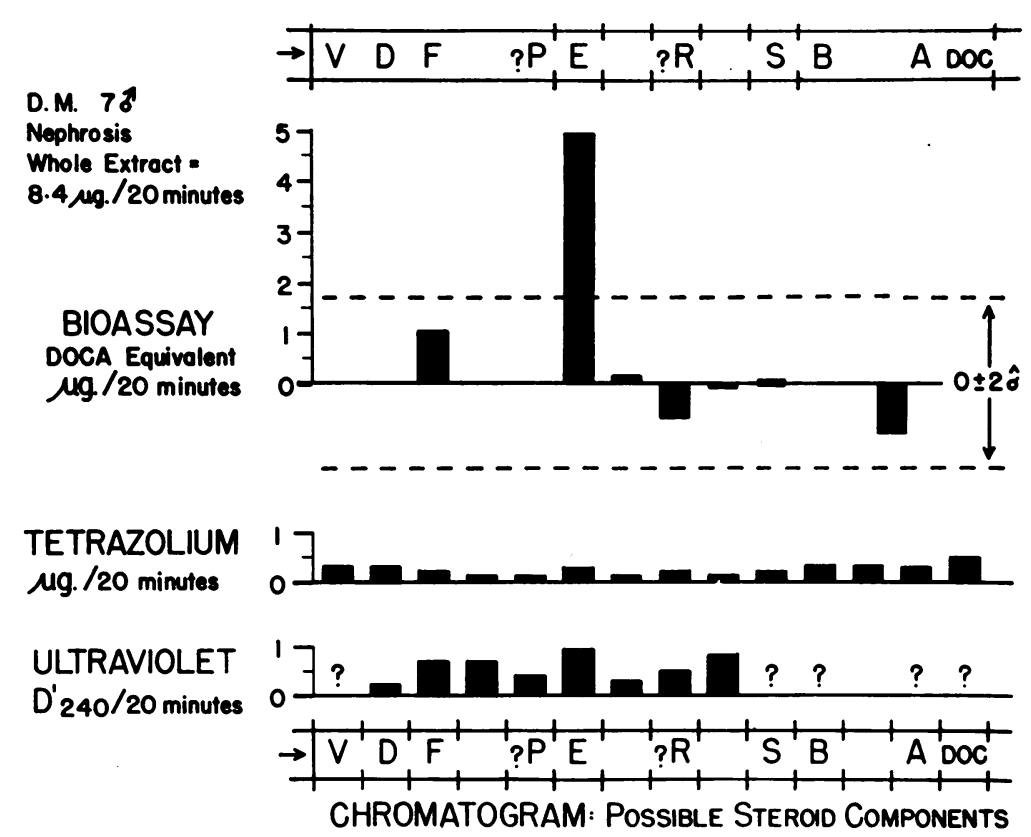

Fig. 7. Sodium-Retaining Activity, Tetrazolium Reduction, and Lltraviolet light Absorption Determined in Elcates from ChromaTOGRAMS (CASE D. M.)

See explanatory note under Figure 6.

very close to the value obtained from the reduction of tetrazolium (Figure 9).

These calculations indicate that the sodiumretaining activity of the final fraction is 15 to 20 times that of desoxycorticosterone, expressed on an equimolar basis.

\section{Normal Male Children}

Extracts of urine from these children did not show significant sodium-retaining activity (Table I).

Figures 10 and 11 summarize the chromatograms of two representative extracts (R. G. and B. L.) in toluene: propylene glycol. No significant sodium-retaining activity was found in the $\mathrm{E}$ fractions. In the older child (B. L.), the fractions moving more slowly than $\mathrm{E}$ caused an appreciably increased excretion of sodium in the bioassay, resembling the effect of the 11-oxy-corticosteroids.

The other two normal children (G. G. and R. A.) gave similar results. Washed extracts showed no appreciable sodium-retaining activity $(0.5$ and $-0.5 \mu \mathrm{g}$. DOCA per 20 minutes in the respective cases). In case G. G., insignificant activity was found in all chromatographic fractions, the $\mathrm{E}$ frac- tion assaying $0.3 \mu \mathrm{g}$. DOCA per 20 minutes. In case $\mathrm{R}$. A., the $\mathrm{E}$ fraction and the fractions moving more slowly than $\mathrm{E}$ produced increased excretion of sodium by adrenalectomized rats.

The possibility remained that cortisone or other components in the $\mathrm{E}$ fraction of normal extracts interfered with the measurement of some sodiumretaining material, but further analysis of the normal $\mathrm{E}$ fraction in benzene: aqueous methanol did not support this interpretation. Very small traces of corticosteroid without detectable sodiumretaining activity were found in the region of the chromatogram in which the strongly sodium-retaining corticosteroid of nephrotic urine had been observed.

\section{DISCUSSION}

These studies support the hypothesis that an adrenal cortical secretion is responsible for the sodium-retaining activity of the lipid extract of urine of children with nephrosis (4). The biological activity was consistently associated with a neutral lipid fraction giving reactions characteristic of an adrenal cortical steroid.

The urine of normal children yielded insig- 


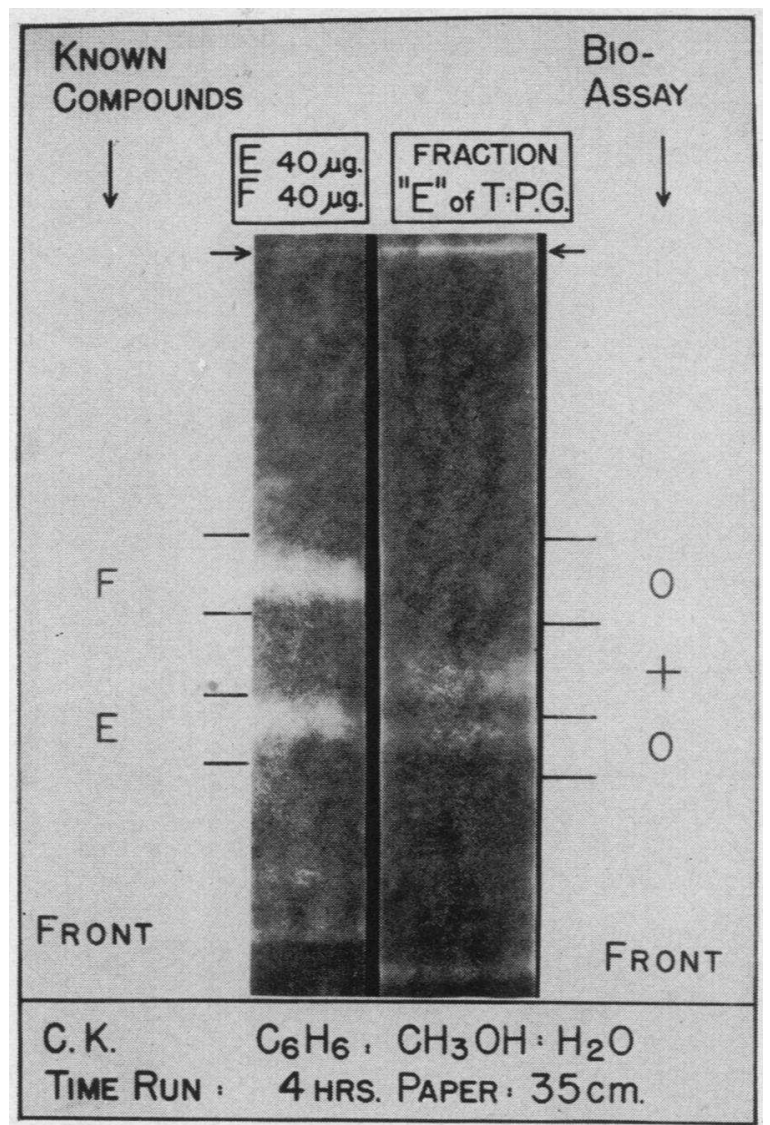

Fig. 8. Descending Chromatogram in Benzene: Aqueous Methanol of "E" Fraction Eluted from Previous Chromatogram in Toluene: Propylene GLYCOL

The $\mathrm{E}$ fraction has been separated in benzene : methanol into at least two components. The component moving just behind cortisone contains the sodium-retaining activity.

nificant sodium-retaining activity and little steroid in a comparable chromatographic fraction.

The nature of the active material is under study at this time. Although none of the known adrenal cortical steroids appears to have all of the properties of the natural material, some inferences can be drawn from points of similarity. The available evidence strongly suggests the presence of a $\Delta^{4}$, 3-keto structure in ring $A$ and of a $\alpha$-ketol side chain on $\mathrm{C}-17$. The chromatographic behavior indicates the presence of one or two additional hydroxyl groups. The infra-red spectrum (17) makes the presence of additional ketone groups unlikely. The high specific sodium-retaining activity argues against the presence of a ketone or $\beta$-hydroxy-substituent at C-11, since such compounds tend to promote the excretion of sodium in the bioassay used. A number of synthetic compounds with various modifications and substitutions in 11-desoxycorticosterone have been tested, but as yet no compound of high specific activity and similar chromatographic behavior has been observed.

As these studies progressed, we were impressed by the similarity of the findings of other investigators (18-20) on the highly active mineralocorticoid of adrenal cortical extract. This material appears to be very similar, if not identical, with the sodium-retaining corticoid of urine. The only important discrepancy concerned absorption of ultraviolet light near $240 \mathrm{~m} \mu$ (18); this has been resolved by the finding of such absorption in later preparations from adrenal cortical extract (16). These points of similarity between the corticoid from adrenal cortex and from urine, prepared from different sources by different methods, and showing consistent activity during purification, support the idea that both preparations contain a natural hormone secreted by the adrenal cortex and appearing in urine in measurable amounts under the observed conditions.

It seems unlikely that secretion of the sodiumretaining corticoid is under the control of the adrenocorticotrophic fraction which regulates the release of the 11,17-hydroxycorticosteroids $(1,5)$.

Sodium-retaining activity has been observed in urine extracts in congestive heart failure $(2,3$, $21)$, pericarditis with tamponade or constriction (3), hypertension (3), nephrosclerosis (3), cirrhosis with ascites (22), and toxemia of pregnancy $(23,24)$, as well as in the nephrotic syndrome $(2-6,24)$. The presence of a high level of sodium-retaining activity in the urine of edematous patients with several diseases suggests a general reaction contributing to the common difficulty with sodium excretion. The stimulus which evokes this reaction is as yet undetermined. The role of reduced dietary intake of sodium can not be overlooked, since normal men, deprived of sodium, may excrete a urine of moderately increased sodium-retaining activity (1). A few controlled observations made in this laboratory indicate that a free intake of sodium only slightly reduces the high level of sodium-retaining activity in the urine of a patient with nephrosis. 


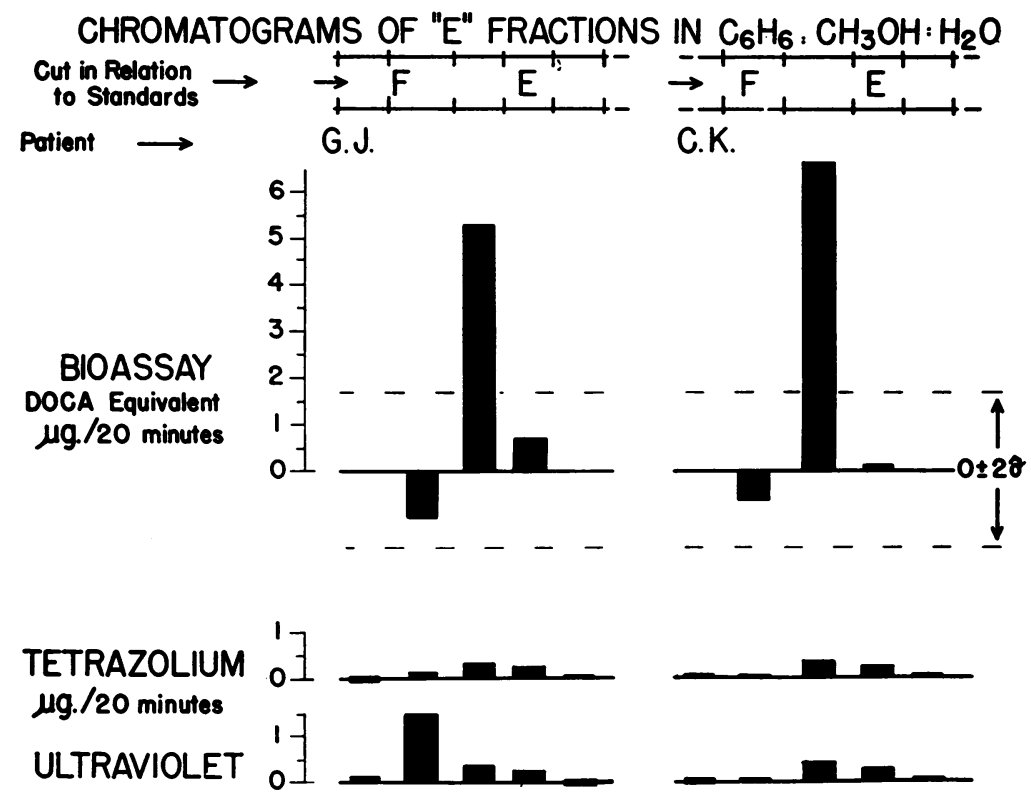

Fig. 9. Sodium-Retaining Activity, Tetrazolicm Reduction, and Litraviolet Light Absorption in Eluates from Benzene: Aqueous Methanol

The method of charting is the same as in Figure 4.

In the benzene: aqueous methanol system, the active fraction moves just more slowly than cortisone. The sodium-retaining activity of this fraction is 15 to 20 times as great as desoxycorticosterone, as may be seen by comparing the height of the bars. Desoxycorticosterone would give bars of equal height for bioassay, "tetrazolium," and "ultraviolet," since all units are expressed as micrograms of this standard steroid.

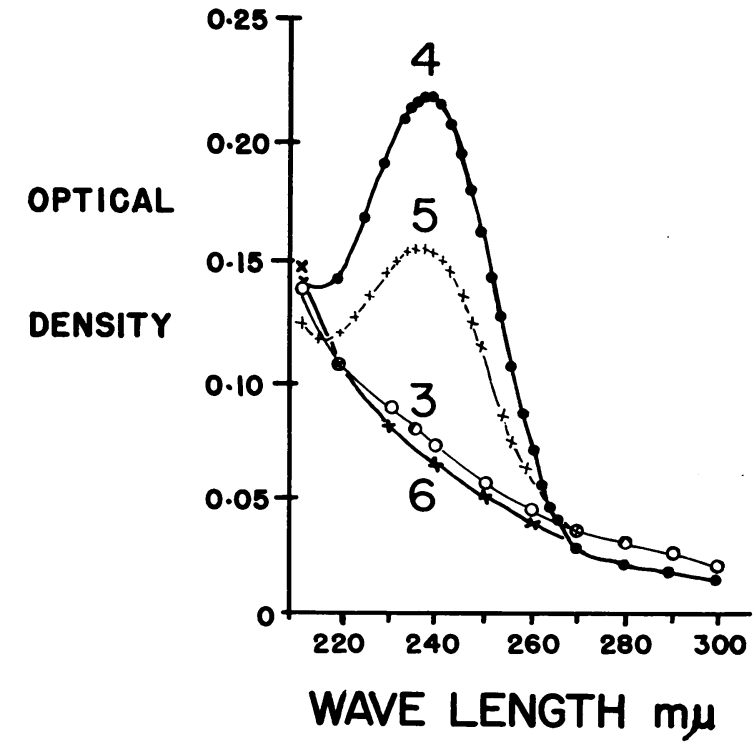

Fig. 10. Absorption Spectra of Eluates from Chromatogram Illustrated in Figure 8

Fraction 4 is the sodium-retaining eluate. Fraction 5 is the eluate of the fraction with a mobility like cortisone. Fractions 3 and 6 are eluates from adjacent areas of paper above and below the bands demonstrated in the photograph.

\section{SUMMARY AND CONCLUSIONS}

Lipid extracts of urine of five children with nephrosis have been fractionated by paper chromatography. The sodium-retaining activity of these extracts resides in a fraction which is presumably of adrenal cortical origin. This material has a specific sodium-retaining activity fifteen to twenty times as great as desoxycorticosterone. None of the known adrenal cortical steroids or their derivatives thus far tested shows the high specific activity and the chromatographic behavior of the sodium-retaining material in urine. The highly active mineralocorticoid of adrenal cortical extract described by Tait and Simpson appears to be very similar, if not identical, to the sodiumretaining corticoid of urine. Available information suggests that the active material is an 11desoxycorticosteroid with one or more oxygencontaining substituents.

Extracts of urine from four normal children on an unrestricted dietary intake of sodium were chromatographed. Neither the extracts nor any 
R.G. 38

$\rightarrow$ V D F $\quad$ ?P $\mathrm{E}_{+}^{+}$?R S B A DOG $^{+}$

Normol

Washed Extract =

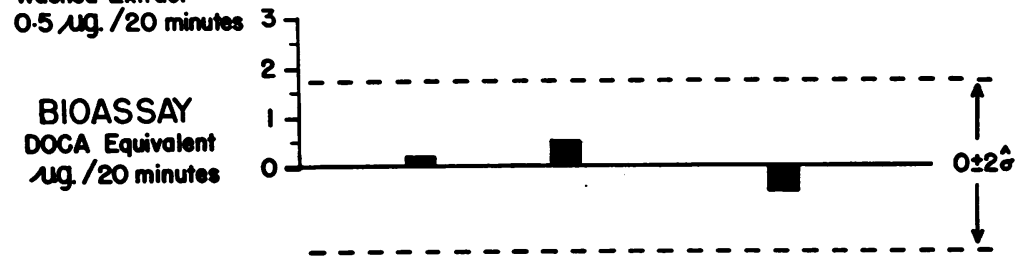

TETRAZOLIUM ug. /20 minutes

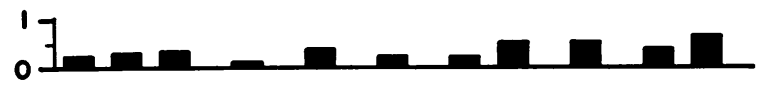

ULTRAVIOLET

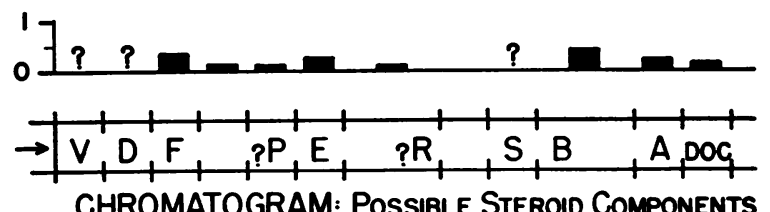

CHROMATOGRAM: POSSIBLE STEROId COMPONENTS

Fig. 11. Sodium-Retaining Activity, Tetrazolium Reduction, and Cltraviolet Light Absorption in Elcates from Toluene: Propylene Glycol Chromatogram (Case R. G., Normal)

See explanatory note under Figure 4.

No sodium-retaining activity was observed. The dosage of urine extract was the same (quantity excreted in 20 minutes) as in the case of patients with nephrosis.

B. L. 118

Normal

Washed Extract =

$-0.3 \mu \mathrm{g} . / 20$ minutes

BIOASSAY

DOCA Equivolent

Ng. $/ 20$ minutes

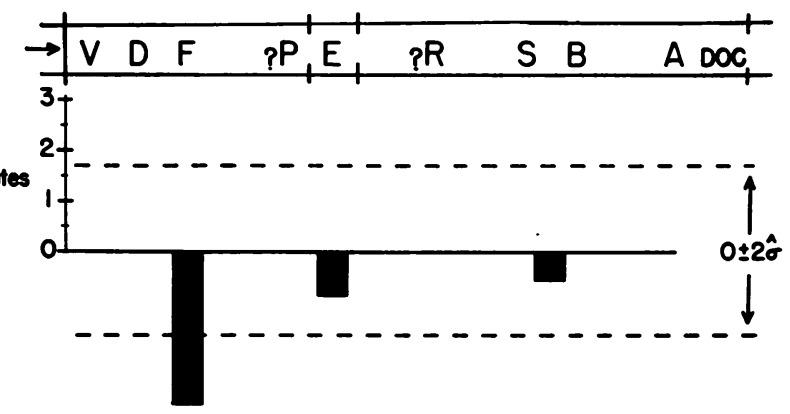

TETRAZOLIUM ug./20 minutes

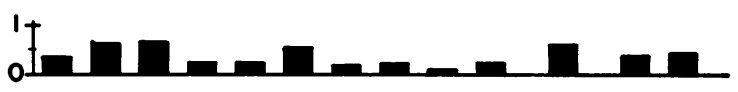

ULTRAVIOLET
$D_{240 / 20 \text { minutes }}^{\prime}$
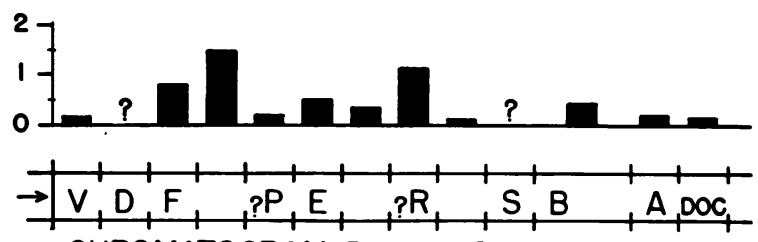

CHROMATOGRAM: Possiele Steroid COMPONENTS

Fig. 12. Sodium-Retaining Activity, Tetrazolium Reduction, and Ultraviolet Light Absorption in Eluates from Toluene: Propylene Glycol Chromatogram (Case B. L., Normal)

No sodium-retaining activity was observed.

The values for tetrazolium reduction and ultraviolet absorption in the $\mathrm{E}$ and $\mathrm{F}$ fractions correspond roughly with the rate of excretion of these steroids described by Burton, Zaffaroni, and Keutmann (25) in normal adults. 
chromatographic fraction showed significant sodium-retaining activity.

\section{ACKNOWLEDGMENT}

The authors' thanks are due to Drs. R. B. Burton, I. E. Bush, and W. J. Haines for advice on methods; to Dr. J. F. Tait and S. A. Simpson for advice and permission to use unpublished information; to Drs. W. J. Haines and H. F. Hailman, The Upjohn Co.; Dr. R. Gaunt, Ciba Pharmaceutical Products; and Drs. E. Alpert and A. Gibson, Merck and Co., for gifts of pure steroids; and to Dr. T. F. Gallagher for observations on infra-red spectra.

\section{REFERENCES}

1. Luetscher, J. A., Jr., and Johnson, B. B., The sodiumretaining corticoid of human urine: Its nature and some physiological factors governing its secretion. J. Clin. Invest., 1953, 32, 585.

2. Deming, Q. B., and Luetscher, J. A., Jr., Bioassay of desoxycorticosterone-like material in urine. Proc. Soc. Exper. Biol. \& Med., 1950, 73, 171.

3. Luetscher, J. A., Jr., and Deming, Q. B., Bioassay of sodium-retaining corticoids and some changes in excretion of these substances in disease. Renal Function, Transactions of the Second Conference, Oct. 19-20, 1950, Josiah Macy, Jr. Foundation, New York, 1951, p. 155.

4. Luetscher, J. A., Jr., and Deming, Q. B., Treatment of nephrosis with cortisone. J. Clin. Invest., 1950, 29, 1576.

5. Luetscher, J. A., Jr., Deming, Q. B., and Johnson, B. B., Treatment of nephrosis with pituitary adrenocorticotrophin. J. Clin. Invest., 1951, 30, 1530.

6. Luetscher, J. A., Jr., Deming, Q .B., and Johnson, B. B., The sodium-retaining activity of the corticoid fraction of urine of oedematous patients, Vol. IVAnterior pituitary secretion and hormonal influences in water metabolism, Ciba Foundation Colloquia on Endocrinology, G. E. W. Wolstenholme, ed., London, J. \& A. Churchill, Ltd., 1952, p. 530.

7. Hyman, E. S., Personal Communication.

8. Luetscher, J. A., Jr., and Johnson, B. B., Chromatographic separation of a corticoid fraction containing sodium-retaining activity from the urine of patients with edema. Am. J. Med., 1953, 15, 417.

9. Burton, R. B., Zaffaroni, A., and Keutmann, E. H., Paper chromatography of steroids. II. Corticosteroids and related compounds. J. Biol. Chem., 1951, 188, 763.

10. Bush, I. E., Methods of paper chromatography of steroids applicable to the study of steroids in mammalian blood and tissues. Biochem. J., 1952, 50, 370 .

11. Haines, W. J., Studies on the biosynthesis of adrenal cortex hormones. Recent Progress in Hormone Research, New York, Academic Press, 1952, vol. 7, p. 255 .

12. Fieser, L. F., and Fieser, M., Natural Products Related to Phenanthrene, New York, Reinhold, 1949.

13. Zaffaroni, A., Micromethods for the analysis of adrenocortical steroids. Recent Progress in Hormone Research, New York, Academic Press, 1953, vol. 8, p. 51 .

14. Mader, W. J., and Buck, R. R., Colorimetric determination of cortisone and related ketol steroids. Anal. Chem., 1952, 24, 666.

15. Johnson, B. B., Bioassay of adrenal cortical steroids on the basis of electrolyte excretion by rats: effects of 11-desoxy and 11-oxysteroids. Endocrinology, in press.

16. Simpson, S. A., and Tait, J. F., Physico-chemical methods of detection of a previously unidentified adrenal hormone. Symposium on the determination of adrenocortical steroids. Memoirs of the Endocrinological Society, Memoir No. 2, London, Dennis Dobson, Ltd., 1953.

17. Gallagher, T. F., Personal communication.

18. Grundy, H. M., Simpson, S. A.; and Tait, J. F., Isolation of a highly active mineralocorticoid from beef adrenal extract. Nature, 1952, 169, 795.

19. Simpson, S. A., Tait, J. F., and Bush, I. E,. Secretion of a salt-retaining hormone by the mammalian adrenal cortex. Lancet, 1952, 263, 226.

20. Grundy, H. M., Simpson, S. A., Tait, J. F., and Woodford, M., Further studies on the properties of a highly active mineralocorticoid. Acta Endocrinol., 1952, 11, 199.

21. Singer, B., and Wener, J., Excretion of sodium-retaining substances in patients with congestive heart failure. Am. Heart J., 1953, 45, 795.

22. Chart, J. J., and Shipley, E. G., The mechanism of sodium retention in cirrhosis of the liver. J. Clin. Invest., 1953, 32, 560.

23. Chart, J. J., Shipley, E. G., and Gordon, E. S., Evidence for a sodium-retaining factor in toxemia of pregnancy. Proc. Soc. Exper. Biol. \& Med., 1951, 78, 244.

24. Singer, B., and Venning, E. H., Method of assay of a sodium-retaining factor in human urine. Endocrinology, 1953, 52, 623.

25. Burton, R. B., Zaffaroni, A., and Keutmann, E. H., Corticosteroids in urine of normal persons determined by paper chromatography. J. Biol. Chem., 1951, 193, 769. 